LETTER • OPEN ACCESS

\title{
Abundance of plastic debris across European and
} Asian rivers

To cite this article: C J van Calcar and T H M van Emmerik 2019 Environ. Res. Lett. 14124051

\section{Recent citations}

$$
\begin{aligned}
& \text { - Wasting the North Sea? - A field-based } \\
& \text { assessment of anthropogenic macrolitter } \\
& \text { loads and emission rates of three German } \\
& \text { tributaries } \\
& \text { Rosanna Isabel Schöneich-Argent et al } \\
& \text { - Rapid Assessment of Floating } \\
& \text { Macroplastic Transport in the Rhine } \\
& \text { Paul Vriend et al }
\end{aligned}
$$

View the article online for updates and enhancements. 


\title{
LETTER
}

CrossMark

OPEN ACCESS

RECEIVED

6 August 2019

REVISED

4 November 2019

ACCEPTED FOR PUBLICATION

5 November 2019

PUBLISHED

11 December 2019

Original content from thi

work may be used under

the terms of the Creative

Commons Attribution 3.0

licence.

Any further distribution of this work must maintain

attribution to the

author(s) and the title of

the work, journal citation

and DOI.

\section{Abundance of plastic debris across European and Asian rivers}

\author{
C J van Calcar ${ }^{1,2}$ (iD) and T H M van Emmerik Em $^{1,3}$ (iD \\ 1 The Ocean Cleanup, Batavierenstraat 15, $3014 \mathrm{JH}$, Rotterdam, The Netherlands \\ 2 Geoscience and Remote Sensing, Delft University of Technology, Stevinweg 1, 2628 CN, Delft, The Netherlands \\ 3 Hydrology and Quantitative Water Management Group, Wageningen University, Droevendaalsesteeg 3, 6708 PB, Wageningen, The \\ Netherlands \\ E-mail: carolinevancalcar@live.nl
}

Keywords: plastic, pollution, rivers, marine litter, plastic composition

Supplementary material for this article is available online

\begin{abstract}
Plastic pollution in the marine environment is an urgent global environmental challenge. Land-based plastics, emitted into the ocean through rivers, are believed to be the main source of marine plastic litter. According to the latest model-based estimates, most riverine plastics are emitted in Asia. However, the exact amount of global riverine plastic emission remains uncertain due to a severe lack of observation. Field-based studies are rare in numbers, focused on rivers in Europe and North America and used strongly varying data collection methods. We present a harmonized assessment of floating macroplastic transport from observations at 24 locations in rivers in seven countries in Europe and Asia. Visual counting and debris sampling were used to assess (1) magnitude of plastic transport, (2) the spatial distribution across the river width, and (3) the plastic polymer composition. Several waterways in Indonesia and Vietnam contain up to four orders of magnitude more plastic than waterways in Italy, France, and The Netherlands in terms of plastic items per hour. We present a first transcontinental overview of plastic transport, providing observational evidence that, for the sampled rivers, Asian rivers transport considerably more plastics towards the ocean. New insights are presented in the magnitude, composition, and spatiotemporal variation of riverine plastic debris. We emphasize the urgent need for more long-term monitoring efforts. Accurate data on riverine plastic debris are extremely important to improve global and local modeling approaches and to optimize prevention and collection strategies.
\end{abstract}

\section{Introduction}

Plastic pollution in the aquatic environment is considered one of the most challenging environmental risks globally. Direct effects of unsoundly disposed plastics include the entanglement of aquatic life and increased flood risks through blockage of urban drainage systems [1, 2]. Over time, plastic debris degrades into microplastics due to photodegradation and abrasion [3], that are later ingested by aquatic fauna and small organisms, such as zooplankton. Plastic enters the food chain of humans and animals, threatening global human and ecosystem health $[4,5]$.

The generation of plastic waste is accelerated by an increasing population, growing economy, and rapid urbanization. Often, waste treatment, recycling, and recovery routes cannot develop at a rate necessary to dispose all the plastic [6]. Of the 6.3 billion tonnes of plastic waste generated until 2015, 79\% accumulated in landfills or the natural environment [7]. Waste management, plastic use regulation, and waste and plastic consumption differs considerably between countries in the world [1]. In turn, these factors impact the amount of plastic entering river systems [8]. The terrestrial and marine transport of plastic items is influenced by local characteristics of the river catchment area, such as land-use, wind, rainfall, river discharge, and hydraulic infrastructure [9-11]. A part of the plastic items will sink or strand in the river and a part will eventually reach the river mouth [12-14]. Yet, plastic transport by rivers is assumed to be the main source of plastic litter in the ocean [8]. However, a 
recent study shows that at least half of the collected plastics of the Great Pacific Garbage Patch in the North Pacific Ocean were objects from marine based sources [15]. Although this study hypothesizes that this is caused by coastal settlement of the plastic, the exact cause of this discrepancy remains unknown. More comprehensive data on the quantity of riverine plastic, the distribution of plastic over the river width, and the riverine plastic composition can contribute to a better understanding of the origin and fate of plastics in aquatic environments, crucial to mitigate the negative impact of plastic pollution.

The amount of plastic litter that is emitted from land to the ocean is estimated globally by several models $[11,16,17]$. These models are generally uncertain due to a lack of data and complexities in the fate and transport of plastics. Model results show that most riverine plastics are emitted in Southeast Asia, but most data driven riverine plastic studies are biased towards European and North American rivers [6] (e.g. the Danube [18], the Thames [19], the Tiber [20], and the Los Angeles basin [21]). Another complicating factor is that plastic transport and composition are often not measured consistently over time and space. While riverine macroplastic debris $(>5 \mathrm{~mm})$ remains understudied, this makes up most of the observed mass on the ocean and poses direct hazards on marine life $[6,8]$. Available studies on riverine plastic debris focus mainly on plastic in rivers with large basins, but these basins are not necessarily the largest contributor to the ocean plastic pollution [22]. These biases impede a global assessment of riverine plastic debris transport, as has been done on marine plastic litter density [23].

Here, we provide a first transcontinental assessment of riverine floating macroplastic debris across 24 sampling sites in seven countries in Asia and Europe. Plastic debris data was collected using a harmonized method at all sites. In addition to several main European rivers (in The Netherlands, France, Italy), we focus on river basins with high amounts of mismanaged plastic waste (in Thailand, Indonesia, Malaysia, and Vietnam [8]), rather than solely large river basins by surface area. We demonstrate that the average magnitude, composition, and distribution over the river width of plastic debris transport varies considerably per river. Our results show that local in situ data is a prerequisite to understand the origin and fate of river plastic debris, and to optimize prevention and collection strategies.

\section{Methods}

\subsection{Plastic transport observations}

Visual counting of plastic debris is an uncomplicated method to determine the plastic transport $[24,25]$ at various sections across the river width. During each measurement, an observer standing on a bridge counted all visible plastic items passing through a predefined section for a period between 1 and $20 \mathrm{~min}$, depending on the plastic load of the river. Each river was divided in 3 to 12 sections, so that the complete river width was covered in one hour at most. Each floating and superficially submerged plastic piece visible was counted, independent of its size. The average minimum debris size was estimated to be $1 \mathrm{~cm}$. If the debris type was uncertain, it was not counted as plastic. For subsequent analysis, the plastic debris counts were normalized over time and expressed in monthly averaged number of plastic items per hour. The number of items per hour per section provide the spatial variation over the river width and the sum of the segments provide the total number of floating pieces of plastic per hour over the whole river width. For each river, it was also determined what percentage of the river width carries $50 \%$ and $90 \%$ of the plastic debris transport, respectively. Data and the code to analyze the data can be found in the supplementary material available at stacks.iop. org/ERL/14/124051/mmedia.

\subsection{Plastic composition}

Plastic composition was determined using net sampling, local available data or visual counting, and the preferred method depended on the local regulations and data availability. For net sampling, trawls were used to sample the upper $40 \mathrm{~cm}$ of the water column. All trawls consisted of frames $(67 \times 50 \mathrm{~cm}$, height $\times$ width $)$, with $2 \mathrm{~m}$ long nets attached. The chosen mesh size of $2.5 \mathrm{~cm}$ was an optimization between the desired size fraction of the plastic catch and the adaptability of the trawl due to the drag force. To increase buoyancy and stability, horizontal buoys were attached on each side of the frame. Depending on the water flow velocity and the plastic load, trawling deployments lasted between $10 \mathrm{~min}$ and a few hours. The trawling locations were determined based on the prevailing flow direction, observed largest debris amount, and the avoidance of navigation routes. The collected plastic was weighted or counted, depending on the location, and separated into 6 categories: polyethylene terephthalate (PET), polystyrene (PS), expanded polystyrene (EPS), hard polyolefin $\left(\mathrm{PO}_{\text {hard }}\right)$, Soft polyolefin $\left(\mathrm{PO}_{\text {soft }}\right)$, and Rest. Note that polyolefins include polyethylene (PE) and polypropylene (PP). Each item was assigned to a polymer category based on their common use:

- PET: transparent plastic bottles;

- PS: products that contain consumables such as plates, cutlery, and cups;

- EPS: foam objects, such as lunch boxes and meat trays;

- $\mathrm{PO}_{\text {hard: }}$ bottle caps, containers, and rigid plastics;

- $\mathrm{PO}_{\text {soft }}$ : bags, foils, and wrappings;

- Rest: all other objects that do not belong to one of the other categories. 


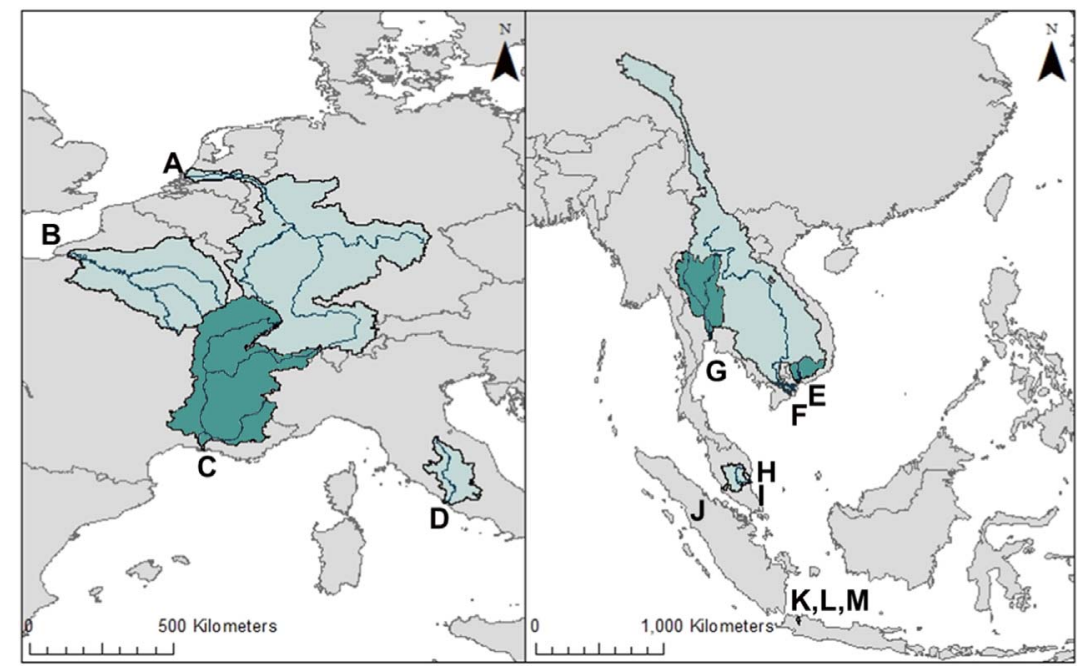

Figure 1. River catchments (indicated in green) and rivers (indicated in dark blue) included in this study. In some cases, the catchment areas cover more then one country. In this case, the country mentioned here is the country where the river mouth is located. A Rhine (The Netherlands), B Seine (France), C Rhône (France), D Tiber (Italy), E Saigon (Vietnam), F Mekong (Vietnam), G Chao Phraya (Thailand), H Pahang (Malaysia), I Klang (Malaysia), J Kuantan (Malaysia), K Ciliwung (Indonesia), L Pesanggrahan (Indonesia), and M Banjir Kanal Timur (Indonesia)

This peer-review method was developed with the aim to provide a practical approach for a first-order characterization. We acknowledge that there is uncertainty introduced. Visual counting was also used to determine the plastic composition of each observed item. The same categories were used as for net sampling. For the Rhine [26] and the Chao Phraya [27], data collected by using litter traps was used to determine the plastic composition by weighing the collected plastic. The results of the analysis of the composition data is divided by mass (net sampling and litter traps) and item count (net sampling and visual counting).

\subsection{Measured waterways}

In total, measurements at 24 waterways in seven countries in Asia and Europe are included in this study (see figure 1). A numeration of these waterways and the characteristics of each location are given in table 1. The period and frequency of counting and sampling vary for each river from $3 \mathrm{~d}$ in total to a weekly assessment for a period of 12 months. All measurements conducted by this study were done in 2018, except the measurements in 2017 in the Tiber and the Rhône, conducted by Crosti et al [20] and CastroJiménez et al [28] respectively.

In Europe, measurements were done in Italy, The Netherlands, and France. Rome (Italy) lies close to the sea and the Tiber is flowing right through the city. This makes this river an interesting location to study plastic pollution close to a river mouth. Results from the study Crosti et al [20] are used in this study. The Rhine was estimated to be the most polluted river of Europe [11]. At the location where the river enters The Netherlands, it splits in several rivers forming a complex river delta. The bridge most close by the river mouth has been chosen to conduct measurements, in the city of Rotterdam. To determine the composition of plastic in the Rhine, debris captured by a litter trap was analyzed [26]. The litter trap was emptied about every month in 2017 and 2018 for in total 22 times and each time, the composition was determined. This results in a mean composition that is used in this study. Paris is one of the largest metropolitan areas in Europe. Therefore plastic transport in the Seine was measured at four locations, one upstream of Paris, two downstream of Paris, and one close to the river mouth. The composition was measured using net sampling. The Rhône river in France flows into the Mediterranean sea. Results from the study Castro-Jiménez et al [28] are used in this study. The plastic flux is measured in the middle of the river, with an observation width of $65 \mathrm{~m}$. In Asia, measurements were done in Vietnam, Indonesia, Thailand, and Malaysia. These are all in the top ten of most plastic emitting countries according to Lebreton et al [11]. The measured locations were selected for various reasons. Several tributaries to the Mekong were chosen as the main river was estimated to be one of the 20 most emitting rivers. The Saigon river traverses a developing South East Asian mega city in Vietnam (Ho Chi Minh City) and drains most of the untreated wastewater from dense urban districts and industrial areas [33]. Four locations in Ho Chi Minh City were chosen as measurement locations, and net sampling was used to determine the composition. The chosen waterways in Indonesia are located in Jakarta, the largest city of Indonesia located right at the Java sea. The waterways here are narrow channels so plastic has a high probability to flow through since it cannot accumulate at the riverbank. Bangkok is Thailand's largest city, and is drained by the Chao Phraya river. Two bridges were chosen to conduct visual counting, 
Table 1. Overview of the waterways where measurements were done. All measurements were performed for this study, except the measurement in the Tiber [20] and the Rhône [28]. The river width refers to the width at the location where the measurements were done. BKT refers to Banjir Kanal Timur and BKB refers to Kanal Banjir Barat.

\begin{tabular}{|c|c|c|c|c|c|c|}
\hline $\begin{array}{l}\text { Measurement } \\
\text { location }\end{array}$ & River & $\begin{array}{c}\text { Watercourse } \\
\text { type }\end{array}$ & Main river & $\begin{array}{l}\text { River } \\
\text { width } \\
(\mathbf{m})\end{array}$ & $\begin{array}{l}\text { Distance to } \\
\text { river } \\
\text { mouth }(\mathbf{k m})\end{array}$ & $\begin{array}{c}\text { Composition } \\
\text { method }\end{array}$ \\
\hline \multicolumn{7}{|l|}{ Italy } \\
\hline $\begin{array}{l}\text { 1. Fiumicino [20] } \\
\text { The Netherlands }\end{array}$ & Tiber & Distributary & Tiber & 31 & 1 & No data \\
\hline \multicolumn{6}{|l|}{ France } & Mass \\
\hline $\begin{array}{l}\text { 3. Villeneuve-le- } \\
\text { Roi [29] }\end{array}$ & Seine & Main river & Seine & 118 & 367 & Item count \\
\hline $\begin{array}{l}\text { 4. Triel-sur- } \\
\text { Seine [29] }\end{array}$ & Seine & Main river & Seine & 145 & 268 & Item count \\
\hline $\begin{array}{l}\text { 5. Meulan-en-Yve- } \\
\text { lines [29] }\end{array}$ & Seine & Main river & Seine & 132 & 260 & Item count \\
\hline 6. Rouen [29] & Seine & Main river & Seine & 133 & 113 & Item count \\
\hline 7. Arles [28] & Rhône & Main river & Rhône & 150 & 50 & No data \\
\hline \multicolumn{7}{|l|}{ Vietnam } \\
\hline $\begin{array}{l}\text { 8. Cau Thu } \\
\text { Thiem [30] }\end{array}$ & Saigon & Main river & Saigon/Dong Nai & 300 & 60 & Mass \\
\hline $\begin{array}{l}\text { 9. Cau Nguyen } \\
\text { Huu Canh }\end{array}$ & Thi Nghe & Urban canal & Saigon/Dong Nai & 65 & 63 & Item count \\
\hline 10. Cau Tan Tuan & Tan Thuan & Urban canal & Saigon/Dong Nai & 97 & 56 & No data \\
\hline 11. Saigon & Saigon & Main river & Saigon/Dong Nai & 300 & 62 & Mass \\
\hline 12. Quang Trung & Can Tho & Tributary & Mekong & 200 & 80 & Item count \\
\hline $\begin{array}{l}\text { 13. Cau Di Bo Ben } \\
\text { Ninh Kieu }\end{array}$ & Rach Cai Khe & Urban canal & Mekong & 178 & 78 & Item count \\
\hline \multicolumn{7}{|l|}{ Indonesia } \\
\hline 14. BKB-Grogol [31] & Ciliwung & Main river & Ciliwung & 24 & 6 & Mass \\
\hline 15. BKB-Angke [31] & Ciliwung & Main river & Ciliwung & 18 & 2 & Mass \\
\hline 16. Haryono [31] & Ciliwung & Main river & Ciliwung & 70 & 17 & Mass \\
\hline $\begin{array}{l}\text { 17. Cengkareng } \\
\text { Kapuk [31] }\end{array}$ & Pesanggrahan & Distributary & Pesanggrahan & 64 & 2 & Mass \\
\hline 18. BKT mouth [31] & BKT & Flood channel & BKT & 48 & 2 & No data \\
\hline \multicolumn{7}{|l|}{ Thailand } \\
\hline 19. Ratchawithi & Chao Phraya & Main river & Chao Phraya & 309 & 30 & Mass \\
\hline 20. Mahaisawan & Chao Phraya & Main river & Chao Phraya & 373 & 22 & No data \\
\hline \multicolumn{7}{|l|}{ Malaysia } \\
\hline 21. Klang [32] & Klang & Main river & Klang & 115 & 10 & Item count \\
\hline 22. Pahang & Pekan & Main river & Pahang & 545 & 9 & Item count \\
\hline 23. Kuantan & Kuantan & Main river & Kuantan & 370 & 1 & Item count \\
\hline 24. Galing & Kuantan & Tributary & Kuantan & 30 & 1 & Item count \\
\hline
\end{tabular}

upstream of the city center and downstream of the city center. Data from an existing litter trap was used to determine the plastic composition [27]. In Malaysia, three rivers has been studied. One river, Klang, that flows through Kuala Lumpur, and two rivers, Kuantan and Pahang, in the east of Malaysia. Net sampling was used in the Klang to determine the plastic composition. The plastic composition in the Kuantan and Pahang was determined visually.

\section{Results}

\subsection{Magnitude of riverine plastic debris transport} An overview of total floating plastic debris transport of 24 waterways in rivers in four Asian and three
European countries, expressed in monthly mean amount of plastic items per hour over the full river width is shown in figure 2. Plastic transport varies between rivers with up to five orders of magnitude, ranging from $10^{0}$ to $10^{4}$ plastic items per hour. Six of the eight studied rivers in Asian countries contain more floating plastic than rivers in Europe. The mean amount of plastic items per hour for Southeast Asia $\left(7.1 \times 10^{3}\right.$ items $\left.^{-1}\right)$ is one order higher than the mean amount of plastic items per hour in Europe $\left(2.5 \times 10^{2}\right.$ items $\left.^{-1}\right)$. The Ciliwung river in Indonesia ranked the highest in total floating macroplastics observed at $2 \times 10^{4}$ items per hour.

Rivers in Indonesia, Vietnam, Malaysia, France, The Netherlands, and Italy were measured multiple times in a year. For these rivers, the difference between 


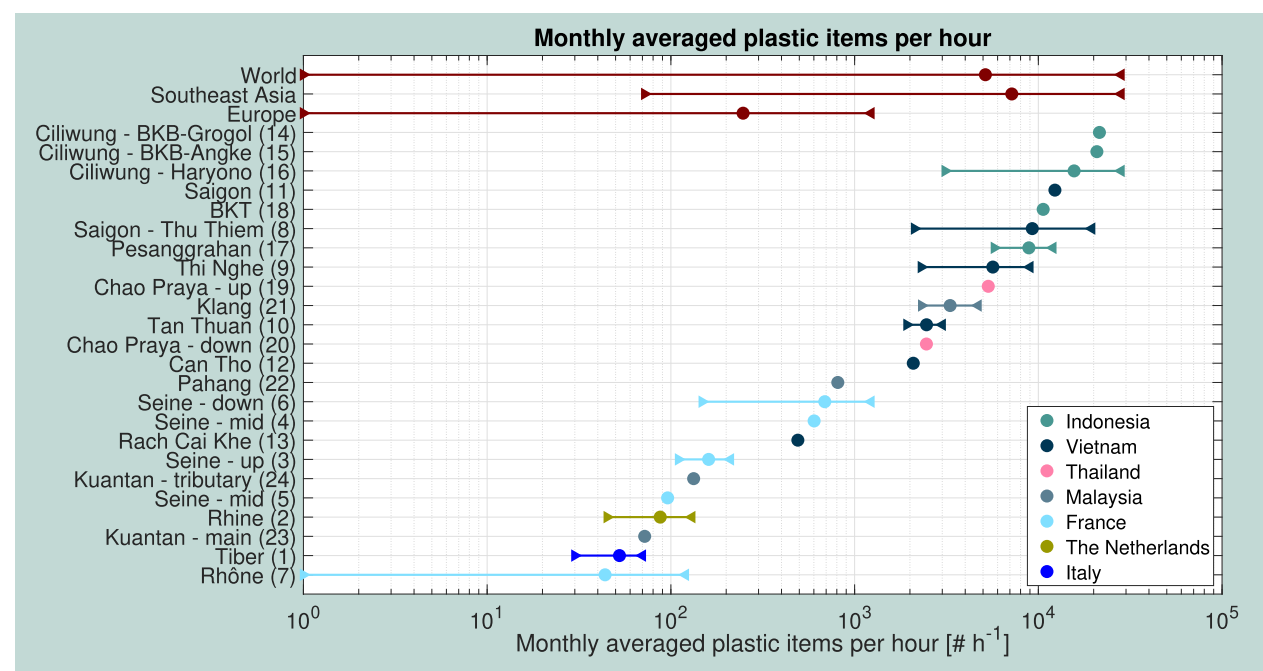

Figure 2. Overview of the mean floating plastic transport for all measured rivers. The top three bars show means taken over all rivers (world), the Asian rivers and the European rivers. Eleven rivers were measured multiple times in a year. For these rivers, the circle corresponds to the yearly mean and the bar corresponds to the minimum and maximum monthly mean. On the vertical axis, the rivers are shown by name and the locations are indicated as up for upstream and down for downstream locations. The indicated numbers correspond to the numeration in table 1 .

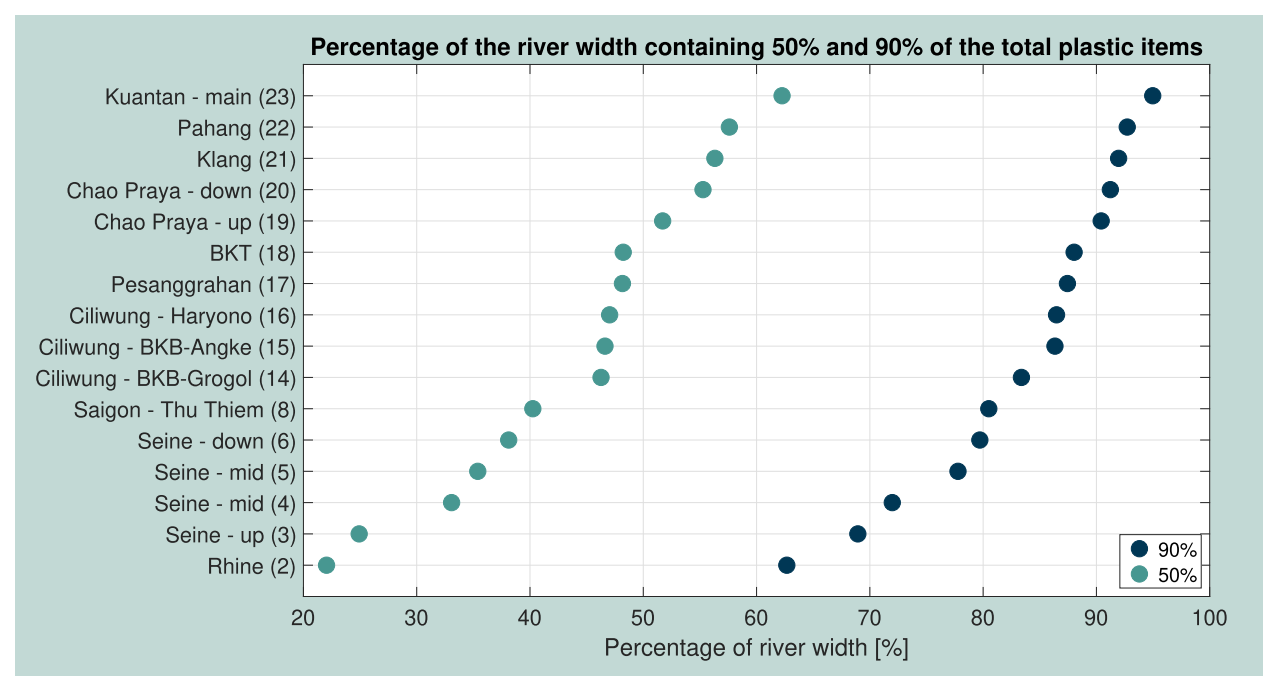

Figure 3. Percentage of the river width through which $50 \%$ and $90 \%$ of the total amount of floating plastic items was transported.

the minimum and maximum monthly mean is shown with a bar in figure 2. Several rivers show variation in monthly mean plastic transport, demonstrating plastic debris transport may exhibit strong seasonality. For example, the variability of plastic transport at Ciliwung - Haryono ranged up to one order of magnitude. The highest transport was measured in November, which is the monsoon season, and the lowest transport in May when the dry season starts.

For Vietnam and Malaysia, the amount of floating plastic varied with several orders of magnitude between rivers in the same country. Even within the same river, plastic transport varied between measurement locations. For example, the mean plastic transport in the Seine river in France was an order of magnitude higher downstream (about $7 \times 10^{2}$ items per $\mathrm{h}$ ) than more downstream (less than $1 \times 10^{2}$ items perh).

\subsection{Distribution of plastic debris over the river width}

Figure 3 shows for each river the percentage of the river width that contains $50 \%$ and $90 \%$ of the plastic debris. This demonstrates that most of the plastic items $(90 \%)$ are distributed over more than half of the river width (69\%-92\% of the width). The difference in spatial variation over the river width between rivers is bigger $(36 \%)$ when considering $50 \%$ of the plastic items. For some locations, such as Ciliwung (BKBGrogol), most plastic can be found in the middle of the river. For other locations, such as the Rhine and Chao Phraya, most plastic can be found at the outer sides of 
the rivers. This is shown in detail per river in figures 5 and 6 in the supplementary material.

\subsection{The composition of floating macroplastic}

For most rivers, the dominant category of plastic is $\mathrm{PO}_{\text {soft }}$ with a mean of $47 \%$ in Europe and $37 \%$ in Southeast Asia. However, the spread between rivers is $20 \%-90 \%$ of the total. Especially in rivers in Indonesia and France the percentage of $\mathrm{PO}_{\text {soft }}$ is high. For two rivers in Vietnam (locations 12 and 13), EPS has also a considerable share in the composition (about 30\%$55 \%$ ). In Malaysia, The Netherlands, and in one river in Vietnam and Indonesia, also $\mathrm{PO}_{\text {hard }}$ and EPS take a significant share in the composition (with a mean of $12 \%$ for Europe and 10\% for Southeast Asia). Overall, PS and PET were found in rivers but are not a major part of the composition.

\section{Discussion}

The results of this study provide a first assessment of the quantification, composition, and spatial temporal variation of floating macroplastic debris in rivers across Asia and Europe. Several waterways in Indonesia and Vietnam contain up to four orders of magnitude more plastic than waterways in Italy, France, and The Netherlands in terms of plastic items per hour. According to recent model estimates, the top 10-20 polluting rivers are mostly located in Asia and account for 67\%-95\% of the global total [11, 17]. Our paper presents observational evidence that, for the sampled rivers, Asian rivers transport considerably more plastics towards the ocean. Concerning the results of individual Asian countries, the same ranking of Asian countries can be found in the top 10 of countries worldwide, when considering the share of plastic waste that is inadequately disposed [16].

The seasonal variation of the floating plastic transport at a location varies with an order of magnitude in the Ciliwung river in Indonesia, and the Saigon river in Vietnam. Similar dynamics were previously reported by a study focused on the Los Angeles river basin, where an increase in plastic transport was measured during the wet season [21]. The variability of the plastic flux in the Rhône ranged up to two orders of magnitude. The highest flux is measured in May, which is spring season in France although one would expect a higher flux in wintertime due to an increase of precipitation. Apart from a modeled estimation of the influence of monsoons on floating macroplastic transport in a river, no detailed studies are done on this topic [11]. Also the influence of extreme flood events is unknown for macroplas tics, whereas for example the amount of microplastics in Mersin bay in the Mediterranean sea show a 14-fold increase after heavy rains [34]. It was recently estimated that $10 \%-20 \%$ of the oceanic plastic pollution in the North Pacific Ocean is caused by the Tohoku tsunami in Japan in 2011 [15]. It may be assumed that flood events also play an important role in the transport of plastic to rivers. Since the variability of the riverine plastic transport over a year can be significant, this should be considered when interpreting the plastic transport in the rivers where the measurements are done in only one time period of the year.

The variation of plastic debris across the river width varies per location. Several rivers have a pronounced preferential side for plastic transport, (for example Chao Praya, location 19, and Saigon, location 8 ), while other rivers show a more symmetrical or evenly distributed pattern (for example Pessanggrahan, location 17). Since $69 \%-92 \%$ of the river width contains $90 \%$ of the floating plastic debris, the plastic is often not concentrated in specific segments of the river.

There are factors that influence the distribution of floating plastic over the river width. First, the difference may be caused by litter traps that lie close by the measurement location and only cover one side of the river. Second, the curvature and shape of a river affects the cross-sectional distribution. The flow velocity is higher in the outer bend of the river, what leads to an increase of the plastic transport. The curvature of a natural river is complex due to the meandering, so it is plausible that the preferred side changes continuously along the river. The observed rivers in Indonesia are mostly straight engineered waterways and it can be expected that plastic in these waterways peak in the middle of the river. Also the amount of plastic debris varies between locations in the same river. These local differences could be caused by the presence of cities, dams, and litter traps close by the measurement location [35]. Concluding, the spatial variation of plastic debris is influenced by environmental characteristics, such as wind and river curvature, and by anthropogenic factors, such as navigation and hydraulic infrastructure. Site specific insights can be used to locally optimize plastic recovery strategies. The variety of the plastic transport and distribution demonstrates the complexity of the transport in urban areas.

The composition of the plastic varies considerably between and within rivers (figure 4), and may depend on local plastic waste management infrastructure [8]. For example, in several countries PET collection systems are set up to encourage people to recycle plastic bottles. This can lead to shares of PET in riverine plastic debris [36]. Our results show that less PET is found in the Rhine in the Netherlands than in, for example, Kuantan and Pahang river in Malaysia. At the moment, there is no data available of municipalitylevel waste generation for different countries but it might explain the different composition between different rivers in the same country [8]. For example, the share of EPS is about $55 \%$ in Can Tho river and $10 \%$ in Thi Nghe canal while both waterways are located in Vietnam. This demonstrates that the composition of floating plastic debris varies within countries and may 


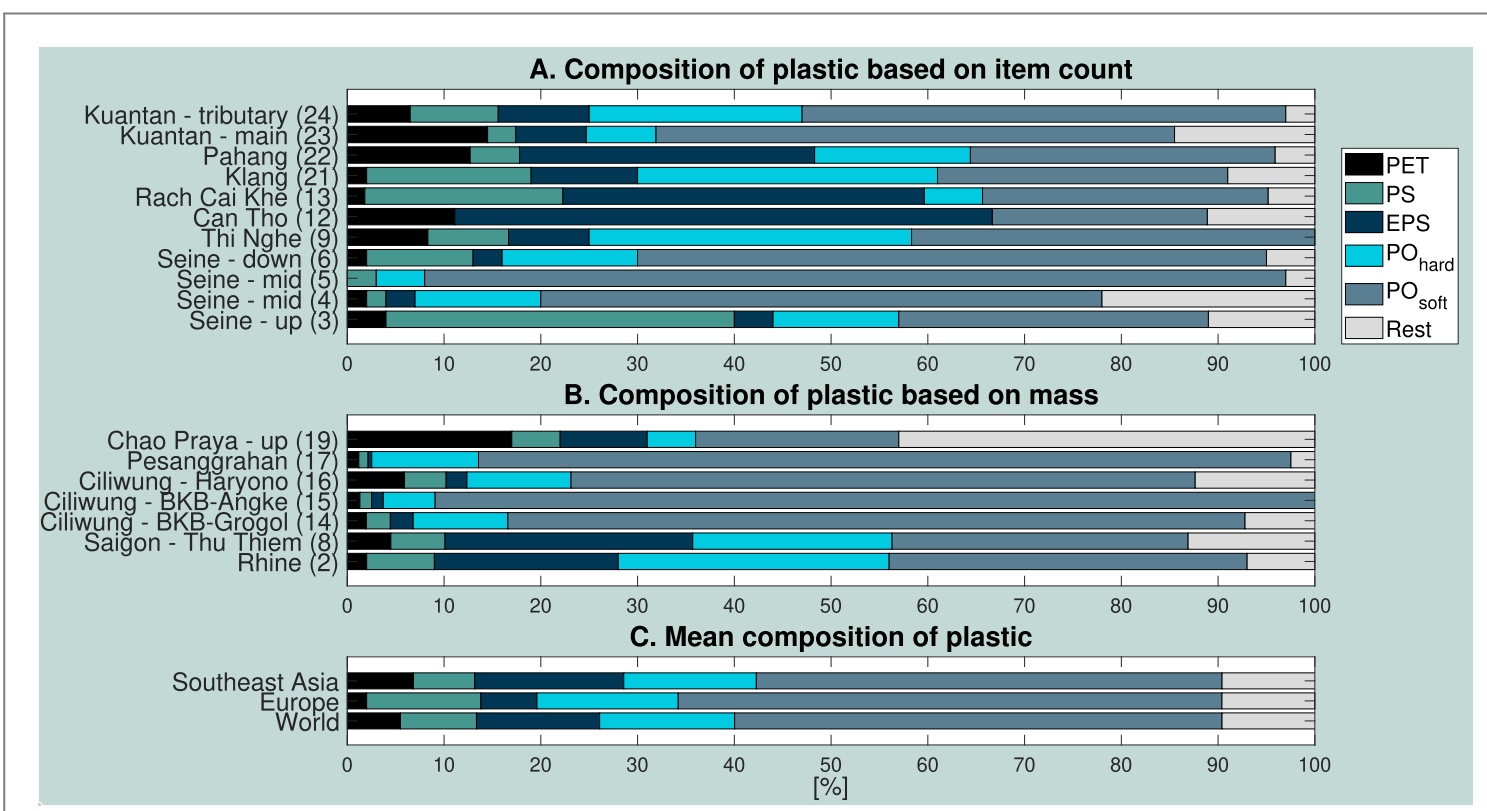

Figure 4. The composition of the plastic samples for locations in Malaysia (Kuantan, Pahang, and Klang), Thailand (Chao Phraya), France (Seine), and The Netherlands (Rhine) in terms of plastic items (figure (A)) or in terms of mass (figure (B)). Figure (C) shows the mean composition for the world, for European rivers (in France and The Netherlands) and for Asian rivers (in Malaysia and Thailand). Plastic items were classified into 6 categories: polyethylene terephthalate (PET), polystyrene (PS), expanded polystyrene (EPS), hard polyolefin $\left(\mathrm{PO}_{\text {hard }}\right)$, Soft polyolefin $\left(\mathrm{PO}_{\text {soft }}\right)$, and Rest. Note that polyolefins include polyethylene $(\mathrm{PE})$ and polypropylene $(\mathrm{PP})$. $\mathrm{PO}$ soft also contains multilayer plastics.

depend on local consumption, management practices, and environmental conditions.

It is often stated that riverine plastic is the major source of marine plastic [8]. On the other hand it is shown that land-sourced plastic is delivered to the open-ocean from nearshore accumulation zones, predominantly as small buoyant fragments [37]. The result of an analysis of 3357 tonnes of debris at 6000 sites at the beach in terms of item count shows that plastic bags are the most common found item (apart from cigarette buds that may not come from the ocean but from direct litter on the beach) [38]. This corresponds to the category $\mathrm{PO}_{\text {soft }}$, which is also most abundant in riverine plastic based on this study. Most items in the top 10 ranking of most common found items, such as plastic cutlery, plates, and straws belong to the category PS. In 2018, the plastic composition in an area of about $300 \mathrm{~km}^{2}$ in the North Pacific Ocean was analyzed using air- and seaborne vessels [15], Over $90 \%$ of the macroplastics was hard plastic, plastic sheet, and film and only about $0.1 \%$ was plastic made of foam (both in terms of item count and mass). Yet, it differs to what extent $\mathrm{PS}$ and $\mathrm{PO}_{\text {hard }}$ are found in riverine plastic in this study (0\%-20\%). This analysis has been done on floating oceanic plastic, but riverine and oceanic plastic can also sink to the ocean floor and be stored in the sediment layers. By comparing the composition of plastic in different environments, such as in sediment layers and surface layers, it follows that only thick-walled, larger plastic debris from low density polymers could be horizontally transported from rivers to ocean through currents [37]. Consequently, this study endorses the hypothesis that buoyant plastic waste in oceans and river originates largely from multiple sources.

Insights in the spatial variation of plastic transport and composition, both over width and length of the river, can be used to optimize riverine plastic collection strategies. The categorization of plastic items based on common use introduces uncertainty. Other categorization methods, for instance OSPAR categorization, may be considered in order to reduce this uncertainty. A comprehensive understanding of the quantity and composition of oceanic plastic is still lacking, therefore it remains inconclusive to what extent riverine plastic is contributing to the total amount of oceanic plastic. For future assessments it is recommended to collect mass statistics of riverine plastic debris, in order to express plastic transport in terms of mass per unit of time. That allows to further explore the relations between plastic production, consumption, leakage into the natural environment, and transport through rivers into the ocean. The overview presented in this study emphasizes the need for longterm measurement efforts. In rivers with the longest data series (Saigon, Ciliwung, Klang, Seine, and Rhône), we demonstrate that plastic transport can have an intraannual variation of at least one order of magnitude.

Our paper presents a first transcontinental overview of plastic transport, providing new insights in the magnitude, composition, and spatiotemporal variation of riverine plastic debris. However, this paper also emphasizes the urgent need for more long-term monitoring efforts. Accurate data on riverine plastic debris are extremely important to improve global $[11,17]$ 
and local [39] modeling approaches and to optimize prevention and collection strategies.

\section{Concluding remarks}

The amount of floating riverine plastic transport was observed to vary between $10^{\circ}$ and $10^{4}$ items per hour. The variation of the total floating plastic transport can differ up to one order of magnitude for different locations within one river. On average, the studied rivers in Asia transport almost 30 times more macroplastic items than the studied European rivers $(7.1 \times$ $10^{3}$ and $2.5 \times 10^{2}$ items $^{-1}$, respectively). Influencing factors on the amount of floating plastic transport are the type of waste management, location of cities, dams, and litter traps, seasonality of rainfall and river discharge, and flood events. This demonstrates the complexity of the origin and fate of riverine plastics.

The horizontal distribution of floating macroplastic over the river width varies across rivers. Half of the plastic items are transported through $22 \%-58 \%$ of the river width and $90 \%$ of the plastic items are transported through $68 \%-92 \%$ of the river width. This means that the plastic is not completely concentrated in a single section of the river.

The composition of the plastic debris can vary up to $45 \%$ points for one polymer type between different rivers in the same country. The composition varies also between locations in one river. This may be caused by differences in plastic consumption and management practices, as well as transport mechanisms, and other factors. The plastic polymer composition can provide information on the type of product that was littered. Therefore, determining the type of plastic can lead to the source of the plastic and hence to improvement of waste management and regulation.

Future assessment should further investigate the role of factors determining plastic transport. In our paper, we demonstrate variation in plastic transport and composition across several European and Asian rivers. Future work should also investigate other hypothesized hot spots of riverine plastic pollution, such as West Africa, Central America, China, India, and the Philippines. The results emphasize that riverine plastic pollution is a global issue and urgent action is needed.

\section{Acknowledgments}

We would like to thank the donors of The Ocean Cleanup who helped funding this study. We are also very grateful to all colleagues at The Ocean Cleanup and research partners who facilitated, and participated in the data collection: Michelle Loozen, Kees van Oeveren, Lourens Meijer, Paul Vriend, Marlein Geraeds, Jelle Kaptein, Colin van Lieshout, Mathijs Bruins, Henning Lagemann and Anna Schwarz (The Ocean Cleanup), Université Paris-Est, Ho Chi Minh University of Technology, Waste 4 Change
Indonesia, Thailand Department of Marine and Coastal Resources, University of Malaysia Pahang, Universiti Teknologi Petronas and Universiti Putra Malaysia (Klang, Malaysia). We thank Boyan Slat, Caitlyn Hall, Renato Borras-Chavez and Anna Schwarz for the valuable feedback that helped improve this paper, and Paul Vriend for his contribution on the river basins map.

\section{Author information}

Contributions. $\mathrm{CvC}$ and $\mathrm{TvE}$ designed the study, $\mathrm{CvC}$ conducted the principal analysis and prepared the initial manuscript, $\mathrm{CvC}$ and $\mathrm{TvE}$ prepared the final manuscript, $\mathrm{CvC}$ prepared the figures.

\section{Competing interests}

The authors declare no competing financial interests.

\section{Data availability}

The data that support the findings of this study are included within this article.

\section{ORCID iDs}

C J van Calcar (10 https:// orcid.org/0000-00034659-0678

T H M van Emmerik (ib https://orcid.org/0000-00024773-9107

\section{References}

[1] UNEP 2018 Single-use Plastics: A Roadmap for Sustainability UNEP

[2] Conchubhair D O, Fitzhenry D, Lusher A, Andrew L, van Emmerik T, Lebreton L, Cicaurte-Villota C, Espinosa L and Rourke E O 2019 Joint effort among research infrastructures to quantify the impact of plastic debris in the ocean Environ. Res. Lett. 14065001

[3] Thompson R C, Barnes D K A, Galgani F and Barlaz M 2009 Accumulation and fragmentation of plastic debris in global environments Phil. Trans. R. Soc. B 364 1985-98

[4] Schwabl P, Köppel S, Königshofer P, Bucsics T, Trauner M, Reiberger T and Liebmann B 2019 Detection of various microplastics in human stool: a prospective case series Ann. Intern. Med. 171 453-7

[5] Barboza L G A, Vethaak A D, Lavorante B R B O, Lundebye A K and Guilhermino L 2018 Marine microplastic debris: an emerging issue for food security, food safety and human health Mar. Pollut. Bull. 133 336-48

[6] Blettler M C M, Abrial E, Khan F R, Sivri N and Espinola L A 2018 freshwater plastic pollution: recognizing research biases and identifying knowledge gaps Water Res. 143 416-24

[7] Geyer R, Jambeck J R and Law K L 2017 Production, use, and fate of all plastics ever made Sci. Adv. 3 e1700782

[8] Lebreton L and Andrady A 2019 Future scenarios of global plastic waste generation and disposal Palgrave Commun. 56

[9] Baldwin A K, Corsi S R and Mason S A 2016 plastic debris in 29 great lakes tributaries: relations to watershed attributes and hydrology Environ. Sci. Technol. 50 10377-85 
[10] Horton A A, Walton A, Spurgeon D J, Lahive E and Svendsen C 2017 Microplastics in freshwater and terrestrial environments: evaluating the current understanding to identify the knowledge gaps and future research priorities Sci. Total Environ. 586 127-41

[11] Lebreton L C M, Van der Zwet J, Damsteeg J W, Slat B, Andrady A and Reisser J 2017 River plastic emissions to the worldas oceans Nat. Commun. 815611

[12] Cózar A et al 2014 Plastic debris in the open ocean Proc. Natl Acad. Sci. 111 10239-44

[13] Ryan P G 2015 Does size and buoyancy affect the long-distance transport of floating debris? Environ. Res. Lett. 10084019

[14] Kukulka T, Proskurowski G, Morét-Ferguson S Meyer D W and Law K L 2012 The effect of wind mixing on the vertical distribution of buoyant plastic debris Geophys. Res. Lett. 39 L07601

[15] Lebreton Let al 2018 Evidence that the great pacific garbage patch is rapidly accumulating plastic Sci. Rep. 84666

[16] Jambeck J R, Geyer R, Wilcox C, Siegler T R, Perryman M, Andrady A, Narayan R and Law K L 2015 Plastic waste inputs from land into the ocean Science 347 768-71

[17] Schmidt C, Krauth T and Wagner S 2017 Export of plastic debris by rivers into the sea Environ. Sci. Technol. 51 12246-53

[18] Lechner A, Keckeis H, Lumesberger-Loisl F, Zens B, Krusch R, Tritthart M, Glas M and Schludermann E 2014 The Danube so colourful: a potpourri of plastic litter outnumbers fish larvae in Europe's second largest river Environ. Pollut. 188 177-81

[19] Morritt D, Stefanoudis P V, Pearce D, Crimmen O A and Clark P F 2014 Plastic in the Thames: a river runs through it Mar. Pollut. Bull. 78 196-200

[20] Crosti R, Arcangeli A, Campana I, Paraboschi M and González-Fernández D 2018 Down to the river: amount, composition, and economic sector of litter entering the marine compartment, through the Tiber river in the western mediterranean sea Rend. Lincei Sci. Fis. Nat. 29 859-66

[21] Moore C J, Lattin G L and Zellers A F 2011 Quantity and type of plastic debris flowing from two urban rivers to coastal waters and beaches of southern California Rev. Gestão Costeira Integrada-J. Integr. Coast. Zone Manage. 11 65-73

[22] Best J 2018 Anthropogenic stresses on the world's big rivers Nat. Geosci. 12 7-21

[23] Li W C, Tse H F and Fok L 2016 Plastic waste in the marine environment: a review of sources, occurrence and effects Sci. Total Environ. 566 333-49

[24] González-Fernández D and Hanke G 2017 Toward a harmonized approach for monitoring of riverine floating macro litter inputs to the marine environment Frontiers Mar. Sci. 486

[25] van Emmerik T et al 2018 A methodology to characterize riverine macroplastic emission into the ocean Frontiers Mar. Sci. 5372
[26] Pikaar R 2018 Shoreliner Rotterdam; Overzicht vangsten van de Shoreliner Tauw

[27] Department of Marine and Coastal Resources and Ministry of Natural Resources and Environment 2018 The Study of Type and Quantity of Floating Marine Debris from Tha Chin and Chao Praya River Mouths by Garbage Boom Thailand

[28] Castro-Jiménez J, González-Fernández D, Fornier M, Schmidt $\mathrm{N}$ and Sempéré R 2019 Macro-litter in surface waters from the Rhone river: plastic pollution and loading to the NW mediterranean sea Mar. Pollut. Bull. 60 66-146

[29] van Emmerik T, Tramoy R, van Calcar C J, Alligant S, Treilles R, Tassin B and Gasperi J 2019 Seine plastic debris transport tenfolded during increased river discharge Frontiers Mar. Sci. 6642

[30] van Emmerik T, Strady E and Kieu-Le T 2019 Seasonality of riverine macroplastic transport Sci. Rep. $911-9$

[31] van Emmerik T, Loozen M, van Oeveren K, Buschman F and Prinsen G 2019 Riverine plastic emission from Jakarta into the ocean Environ. Res. Lett. 14084033

[32] Geraeds M, van Emmerik T, de Vries R and bin Ab Razak MS 2019 Riverine plastic litter monitoring using unmanned aerial vehicles (UAVs) Remote Sens. 112045

[33] Lahens L, Strady E, Kieu-Le T, Dris R, Boukerma K, Rinnert E, Gasperi J and Tassin B 2018 Macroplastic and microplastic contamination assessment of a tropical river (Saigon river, Vietnam) transversed by a developing megacity Environ. Pollut. 236 661-71

[34] Gündoğdu S, Çevik C, Ayat B, Aydoğan B and Karaca S 2018 How microplastics quantities increase with flood events? An example from Mersin Bay NE Levantine coast of Turkey Environ. Pollut. 239342-50

[35] Gasperi J, Dris R, Bonin T, Rocher V and Tassin B 2014 Assessment of floating plastic debris in surface water along the Seine river Environ. Pollut. 195 163-6

[36] Hoppe T, Bressers H, de Bruijn T and Garcia L F 2013 Street litter reduction programs in The Netherlands: reflections on the implementation of the Dutch litter reduction program for 2007-2009 Environ. Eng. Manage. J. 12 1657-68

[37] Schwarz A E, Ligthart T N, Boukris E and van Harmelen T 2019 Sources, transport, and accumulation of different types of plastic litter in aquatic environments: a review study Mar. Pollut. Bull. 92 100-43

[38] Kershaw P, Katsuhiko S, Lee S and Woodring D 2011 Plastic debris in the ocean UNEP Yearbook 2011 (Nairobi: United Nations Environment Programme) pp 20-33

[39] Tramoy R, Gasperi J, Dris R, Colasse L, Fisson C, Sananes S, Rocher V and Tassin B 2019 Assessment of the plastic inputs from the seine basin to the sea using statistical and field approaches Frontiers Mar. Sci. 6 151-6 